OPEN ACCESS

Edited by:

Juliana Morales-Castro, Durango Institute of Technology, Mexico

Reviewed by:

Pranita Jaiswal,

Indian Council of Agricultural Research (ICAR), India

Somnath Mandal, Uttar Banga Krishi

Viswavidyalaya, India

*Correspondence:

Juan G. Báez-González juan.baezgn@uanl.edu.mx

Specialty section:

This article was submitted to Nutrition and Sustainable Diets,

a section of the journal

Frontiers in Nutrition

Received: 04 February 2021

Accepted: 06 May 2021

Published: 31 May 2021

Citation:

Gallardo-Rivera CT, LU A,

Treviño-Garza MZ, García-Márquez E, Amaya-Guerra $C$, Aguilera $C$ and Báez-González JG (2021) Valorization of Almond (Prunus serotina) by Obtaining Bioactive Compounds.

Front. Nutr. 8:663953. doi: 10.3389/fnut.2021.663953

\section{Valorization of Almond (Prunus serotina) by Obtaining Bioactive Compounds}

\author{
Claudia T. Gallardo-Rivera ${ }^{1}$, Analía Lu ${ }^{1}$, Mayra Z. Treviño-Garza ${ }^{1}$, \\ Eristeo García-Márquez ${ }^{2}$, Carlos Amaya-Guerra ${ }^{1}$, Carlos Aguilera ${ }^{1}$ and \\ Juan G. Báez-González ${ }^{1 *}$ \\ ${ }^{1}$ Universidad Autónoma de Nuevo León, Facultad de Ciencias Biológicas, Departamento de Alimentos, Laboratorio de \\ Reologia, San Nicolás de los Garza, Mexico, ${ }^{2}$ Centro de Investigación y Asistencia en Tecnología y Diseño del Estado de \\ Jalisco, A.C., Autopista Mty-Aeropuerto Km 10 Parque PIIT, Apodaca, Mexico
}

The Capulin almond is a seed of the Prunus serotina (var. capuli) that belongs to the Rosaceae family. In this study, the valorization of the Capulin almond was performed by extracting antioxidants contained in the shell, paste, and oil (extracted by manual cold pressing process) of Prunus serotina treated with methanol, ethanol, acetone, and acidified water $(\mathrm{pH} 4)$ in a ratio of $1: 5(\mathrm{w} / \mathrm{v})$. Total phenols were performed using the Folin-Ciocalteu method and expressed as gallic acid equivalents (GAE), antioxidant activity was determined by ABTS and DPPH methods and expressed as Trolox equivalents (TE). Finally, the total flavonoids were determined using a catechin calibration curve and reported as catechin equivalents (CE). The highest extraction of total phenols in shell was obtained with methanol (1.65 mg GAE/g sample) and the lowest using acidified water (0.97 mg GAE/g sample). However, extraction with acidified water favored this process in the paste (1.42 $\mathrm{mg} \mathrm{GAE} / \mathrm{g}$ sample), while the use of solvents did not influence it significantly (0.72 to $0.79 \mathrm{mg} \mathrm{GAE} / \mathrm{g}$ sample). Regarding the total flavonoids, the values for the shell, paste, and oil were of $0.37,0.78$, and $0.34 \mathrm{mg} \mathrm{CE} / \mathrm{g}$ sample, respectively, while that corresponding to the antioxidant activity evaluated with ABTS and DPPH were of 1527.78, 1229.17, $18894.44 \mu \mathrm{M}$ TE/g, and, 568.45, 562.5 and $4369.05 \mathrm{mM}$ TE/g sample, respectively. Finally, our results suggest that by-products such as the shell, paste, and oil obtained from Prunus serotina (var. capuli) represent a potential alternative for the recovery of bioactive compounds with antioxidant activity such as phenolic compounds and flavonoids.

Keywords: antioxidants, shell, paste, Prunus serotina oil, Capulin almond

\section{INTRODUCTION}

The Prunus serotina tree, belonging to the Rosacea family, produces the Capulin fruit as a globose reddish-black drupe at maturity 12 to $20 \mathrm{~mm}$ in diameter, which contains an almond inside. This botanical variety is part of the four varieties (alabamensis, capuli, rufula and serotina) constituting the classification cited by Guzman et al. (1). Its geographical distribution includes southern Mexico, Guatemala, the United States and Canada (2). The Prunus serotina tree grows in mountainous regions at altitudes of 2,500 m or more in the Valley of Mexico and Guanajuato, as well as from Jalisco to Chiapas. In Mexico, the annual production of Capulin fruit was 184.87 tons, and it has 
been used since colonial times in the treatment of cardiovascular, respiratory and gastrointestinal diseases (3). Recent studies show that Prunus species may protect against metabolic syndrome, which includes sensitivity to insulin, visceral obesity, dysregulated metabolism of glucose and lipid, and hypertension. It can also be used to treat stress, immune problems, and anemia, as well as improve brain function (4-7). The Capulin fruit is consumed fresh and dehydrated, as snack and ingredient in processed foods such as jellies, jams and liqueurs $(8,9)$. The Capulin almond is comprised of three parts: the edible part of the almond (kernel), which has a thin shell (skin) that wraps around the kernel, the skin, and an external part called the shell. Various studies have shown that almond by-products (of the kernel, skin, and shell) contain bioactive compounds such as phenolic compounds (flavonoids and phenolic acids) and terpenoids (sterols and triterpenoids), whose composition and quantity depend on factors such as the geographical distribution, origin, environmental conditions, exposure to pests, UV radiation, harvest maturity and obtaining and extraction process (10-14). These by-products are a source of potent antioxidants for the control of oxidative processes, natural antimicrobials, prebiotic and antiviral compounds (15-18).

The almond of Prunus serotina is a source of lipids, raw fiber, humidity, and carbohydrates, in addition to containing vitamin $\mathrm{E}$ and minerals such as $\mathrm{Ca}, \mathrm{Fe}, \mathrm{Mg}, \mathrm{P}, \mathrm{K}, \mathrm{Zn}$, and $\mathrm{Na}(8)$. The Capulin almond stands out for its high level of $\propto$-eleostearic acid (27\%), which is effective in the suppression of the growth of cancer cells and possesses antihypertensive properties due to the presence of vasodilator compounds, such as urosolic acid and uvol. It is also effective as an antiparasitic and antimicrobial $(4,6,19)$. Tests on the oil extracted from Prunus serotina seeds (with hexane and supercritical $\mathrm{CO}_{2}$ ), have shown that the oil was highly polyunsaturated with predominant content of oleic acid (35\%), followed by $\propto$-eleostearic (27\%), linoleic (27\%), palmitic (4\%), stearic (4\%), and $\beta$-eleostearic (1\%) acids (20). Studies in Prunus amygdalus Batsch ssp dulce in the kernel of the almond indicate a range in oil content of 36.76 to $79 \%$, depending on the genotype and a total content of polyphenols between 23.75 and $98.67 \mathrm{mg} \mathrm{GAE} / 100 \mathrm{~g}$, with and antioxidant activity between 44.59 and $91.18 \%$ using DPPH (1,1-diphenyl-2-picrylhidrazyl). Likewise, the presence of $\mathrm{K}, \mathrm{P}$, and $\mathrm{Ca}$ as predominant minerals was determined (16).

The analyzes in Prunus dulcis Mill D.A. Webb show that the kernel of the ripe almond contains around 50\% lipids, $25 \%$ protein and $\sim 20 \%$ carbohydrates. It has a low moisture content and various bioactive compounds in small amounts. The polyphenols are some of these compounds that are related to the quality of the almond and help to increase its shelf-life. Regardless of the type of almond, it has been reported that polyphenols have been seen in a range of 61 to $162 \mathrm{mg} / 100 \mathrm{~g}$. However, flavonoids ( 87 to $135 \mathrm{mg} / 100 \mathrm{~g}$ ) are by far the most abundant compounds in almonds. Some studies indicate that the quality of the kernel of the almond depends on the harvest time, increases in the lipid content and decreases in the carbohydrate and protein content. Late harvest may increase antioxidant activity, suggesting that antioxidant compounds develop late in ripening (19). Additionally, almond, walnut, and pine nut shells have been studied by recovering their bioactive compounds. It was found that the ethanol-water extracts contained total polyphenols, flavonoids, condensed tannins and antioxidant activity values of $\mathrm{IC}_{50} 7.9,15.2$ and $8.2 \mu \mathrm{g} / \mathrm{L}$, respectively. Moreover, the chemical composition and structure of the shell confers brittleness and fracture behavior. The chemical differences between these are also found in the content of polysaccharides, hemicellulose profile and extractives. The foregoing suggests a potential for the reuse mainly of polysaccharides (hemicellulose and lignin) (21). The polyphenols extracted from the Prunus dulcis almond have shown their potential use as a natural dietary antioxidant whose effect depends on its composition and bioavailability. Its content in this almond is comparable to nutrients such as lipids and fiber (8).

The kernel of this almond stands out for its nutritional and commercial value. However, its by-products such as skin, shell and hull are distinguished by their content of phenolic acids and flavonoids that can be used with applications in food and cosmetic formulations. The skin constitutes $4 \%$ of the total weight of the almond but contains between 60 and $80 \%$ of the total phenolic compounds present in the seed. Regarding the almond shell, it is composed of cellulose (29.8 to 50.7\%), hemicellulose (19.3 to $29 \%$ ) and lignin (20.4 to $50.7 \%$ ). The almond shell constitutes 35 to $62 \%$ of the total weight of the fresh almond, whose weight differs significantly due to variety and agronomic factors. It is peel has been reported to contain 18 to $30 \%$ sugar, 2.1 to $8.8 \%$ protein, 10 to $24.9 \%$ crude fiber, cellulose from 20.6 to $35.2 \%$, and crude lignin in a range of 7.5 to $15.6 \%(5,12,22)$.

Various studies report the total content of phenolic compounds in the kernel $(8 \pm 1 \mathrm{mg} \mathrm{QCE} / \mathrm{g}$ ethanolic extract to $8.1 \pm 1.75 \mathrm{mg} \mathrm{CE} / \mathrm{g}$ ethanolic extract), skin $(87.8 \pm 1.75 \mathrm{mg} \mathrm{CE} / \mathrm{g}$ ethanolic extract to $88 \pm 2 \mathrm{mg}$ QCE/g ethanolic extract), shell (38 $\pm 3.30 \mathrm{mg}$ GAE/g methanolic extract) and hull $(71.1 \pm 1.74$ $\mathrm{mg} \mathrm{CE} / \mathrm{g}$ ethanolic extract to $78.2 \pm 3.41 \mathrm{mg}$ GAE/g methanolic extract) of the almond (Prunus amygdalus L.) (9, 23, 24). These antecedents show the viability in the valorization of various types of Prunus almond focused on the extraction of the oil from the skin and shell. The objective of this study was to value the by-products (shell, paste and oil) of the Prunus serotina almond through the manual cold pressing process $\left(30^{\circ} \mathrm{C}\right)$. Considering the content of phenolic compounds and flavonoids in these by-products, the Prunus serotina almond is an alternative for the recovery of more valuable by-products than that of the Prunus dulcis almond, which is the most studied seed.

\section{MATERIALS AND METHODS}

The Capulin almond was purchased in a local market in Mexico City. We used analytical solvents such as ethanol, methanol, acetone, hexane, boric acid, phosphoric acid, hydrochloric acid, butanol, glacial acetic acid, isooctane, propanol, boron trifluoride, heptane, potassium persulfate, ammonium thiocyanate, chloride barium, and sulfate ferrous anhydrous (JT Baker reagents, Mexico). Organic compounds such as Folin and Ciocalteu, gallic acid, catechin hydrate, 
(2,2'-azinobis 3-ethylbenzohtiazoline-6 sulfonic acid) ABTS, DPPH, Trolox, 1,1,3,3-Tetraethoxypropane, thiobarbituric acid acquired from Sigma-Aldrich (Sigma-Aldrich, Mexico) were also utilized.

\section{Extraction Oil}

The seed of the Capulin almond was obtained by a cracking process (as seen in Figure 1) using a sterilized metal squeezer and was stored in airtight bags at $-20^{\circ} \mathrm{C}$ until used. The oil was extracted from seed ( $100 \mathrm{~g}$ ) by manual cold pressing (Henan Wecare Industry Co. Ltd, China) at a temperature of $30^{\circ} \mathrm{C}$; the oil and paste of Prunus serotina by-products were stored in amber jars and hermetic bags at $-20^{\circ} \mathrm{C}(25)$ (Figure 2) until later use.

\section{Preparation of Samples of Almond By-Products}

The extraction of antioxidants compounds in by-products of Prunus serotina such as oil (manual cold pressed), paste (kernel + skin), and shell was carried out with the procedure of Pinelo et al. (26). We mixed $1 \mathrm{~g}$ of oil with a solvent (such as ethanol, methanol, acetone (all at 96\%) and acidified distilled water ( $\mathrm{pH} 4)$ for $4 \mathrm{~min}$ in a vortex, after which the suspension was separated using a centrifuge at 3,000 rpm for $5 \mathrm{~min}$ (LABORTECHNK, Wehingen, Germany) (27). The paste and shell were ground individually in a food processor (NUTRIBULLET, China) (Figure 2), each sample being mixed with solvent (w/v) in a 1:5 ratio and placed in a water bath $\left(50^{\circ} \mathrm{C}\right)$ with magnetic stirring for $90 \mathrm{~min}$. The solids were separated by centrifugation at $800 \mathrm{rpm}$ for $5 \mathrm{~min}$ and the supernatant collected for further analysis (28).

\section{Total Phenolic Compounds}

The total phenolic compounds extracted with the different solvents were quantified according to the Singleton et al. (29) procedure with some modifications. The sample of supernatant $1,000 \mu \mathrm{L}$ obtained from oil, paste, and shell mixed with $100 \mu \mathrm{L}$ of Folin and Ciocalteu reagent $1 \mathrm{~N}$ was allowed to stand for $\sim 5 \mathrm{~min}$. Then $300 \mu \mathrm{L}$ of sodium carbonate $20 \%$ was added and adjusted to a volume of $2,700 \mu \mathrm{L}$ with distiller water, the mixture was kept a rest for $90 \mathrm{~min}$ in dark condiction. We measure the absorbance of the sample with a previous rest of $90 \mathrm{~min}$ at $765 \mathrm{~nm}$ using a UV spectrophotometer in dark condition at $25 \pm 2^{\circ} \mathrm{C}$ (Thermo Fisher Scientific Equipment, MA, USA). The calibration curve was obtained with Gallic acid in a concentration range of 0 to $53 \mathrm{mg} / \mathrm{L}$. The content of phenolic compounds was reported as the mg gallic acid equivalents/g of extract (mg GAE/g) (30). Finally, in order to homologate the use of the solvent in the extraction process of the bioactive compounds from almond byproducts, we decided to use ethanol as solvent in the subsequent evaluations since it showed a good yield and content of total phenols (26). The solvent yield was determined according to the following equation:

$$
\text { Yield }(\%)=\frac{\text { Final volume of solvent }}{\text { Initial volume of solvent }} \times 100
$$

\section{Total Flavonoids}

Flavonoid compounds were analyzed by the colorimetric method proposed by Esfahlan et al. (9) with slight modifications. We mixed $250 \mu \mathrm{L}$ of sample extract (shell, oil and paste) with 1,225 $\mu \mathrm{L}$ of distilled water contained in a glass cell, $75 \mu \mathrm{L}$ of $\mathrm{NaNO}_{2}$ $5 \%, 150 \mu \mathrm{L}$ of $\mathrm{AlCl}_{3} 10 \%$ and $500 \mu \mathrm{L} \mathrm{NaOH}$ (1M) added with a time difference of $5 \mathrm{~min}$, respectively. We measured the absorbance with a spectrophotometer (Thermo Fisher Scientific, MA, USA) at $510 \mathrm{~nm}$ before $30 \mathrm{~min}$. The standard curve made using catechins in an range of 1.6 to $16 \mathrm{mg} / \mathrm{L}$. The results of the triplicate test were expressed for each by-product as catechin equivalents/g of extract (mg CE/g).

\section{Antioxidant Activity Method ABTS (2,2'-Azino-bis \\ (3-Ethylbenzothiazoline-6-Sulphonic Acid)}

The antioxidant activity was evaluated using the Fernandes et al. (31) method with some modifications. The radical ABTS was prepared by mixing potassium persulfate $(2.45 \mathrm{mM})$ and ABTS $(7 \mathrm{mM})$ in a $1: 1$ ratio $(\mathrm{v} / \mathrm{v})$, and the solution stored in a dark environment for $16 \mathrm{~h} .200 \mu \mathrm{L}$ of radical ABTS diluted with $10 \mathrm{ml}$ of ethanol (96\%). The resulting solution showed an absorbance of $0.700 \pm 0.05$ absorbance at $734 \mathrm{~nm}$ in a UV spectrophotometer (Thermo Fisher Scientific, MA, USA). The standard curve was generated using Trolox in a concentration interval of 25 to 505 $\mu \mathrm{mol}$. After adjusting the optical density, the $100 \mu \mathrm{L}$ of the extract prepared with $2,000 \mu \mathrm{L}$ of ABTS radical (by triplicate). This mixture was homogenized and analyzed at $734 \mathrm{~nm}$ (then $7 \mathrm{~min}$ applying the mixture). The results were expressed as $\mu$ mol equivalent of Trolox/g sample ( $\mu \mathrm{M}$ TE/g sample) (32). In addition, the ABTS radical scavenging activity was determined according to the following equation:

$$
\begin{aligned}
& \text { Inhibition (\%) } \\
& =\frac{\text { Absorbance of ABTS solution }- \text { Absorbance of sample }}{\text { Absorbance of ABTS solution }} \times 100
\end{aligned}
$$

\section{Method DPPH}

\section{(2,2-Diphenyl-1-Picrylhydrazyl)}

The antioxidant activity was evaluated according to the Moosavi et al. (33) method to corroborate the behavior obtained by the ABTS method and inhibition of radicals from phenolic compounds. In this method, the DPPH (2,2-diphenyl-1picrilhydrazyl) radical generated by the addition of $96 \%$ ethanol to a $0.1 \mathrm{mM}$ solution of DPPH until absorbance values reached 1 to $571 \mathrm{~nm}$ was measured with UV spectrophotometer (Thermo Fisher Scientific, MA, USA). The standard curve was obtained with Trolox in a concentration range of 25 to $505 \mu \mathrm{mol}$. We mixed $50 \mu \mathrm{L}$ of the sample extract and $2,000 \mu \mathrm{L}$ of the DPPH radical, and the mixture remained in the dark, for $30 \mathrm{~min}$ at $25 \pm 2{ }^{\circ} \mathrm{C}$ to measure the absorbance at $517 \mathrm{~nm}$. The results of the triplicate analysis were expressed as $\mu$ mol equivalent of Trolox/g sample ( $\mu \mathrm{M}$ TE/g sample) (32). In addition, the $\mathrm{DPPH}$ radical scavenging activity was determined according to the following equation:

$$
\begin{aligned}
& \text { Inhibition (\%) } \\
& =\frac{\text { Absorbance of DPPH solution }- \text { Absorbance of sample }}{\text { Absorbance of DPPH solution }} \times 100
\end{aligned}
$$




\section{Capuli almond}

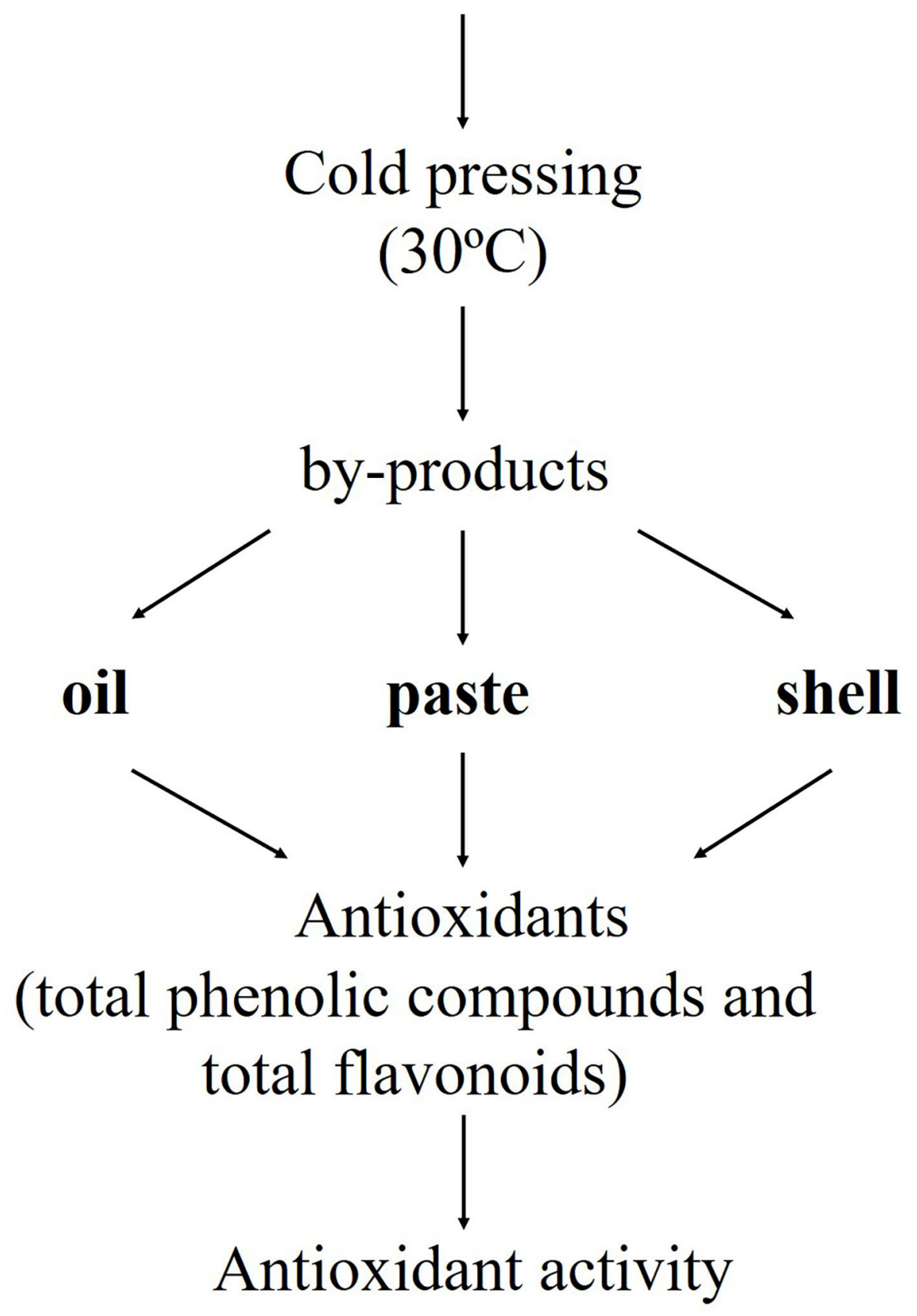

FIGURE 1 | Process of valorization of the Prunus serotina (var. capuli) almond.

\section{Statistical Analysis}

Data analysis was performed by calculating the mean value and standard deviation of the triplicate determinations to evaluate their repeatability. It was determined that there is a significant difference between the means (at $\mathrm{p} \leq 0.05)$ through a completely random analysis of variance (ANOVA). Finally, the multiple comparison of significant means was evaluated using the Tukey test.

\section{RESULTS}

Solvent Yields and Total Phenol Extraction

Figure 3 shows the yields of various solvents (ethanol, methanol, acetone and, acidified water) used to obtain total phenolic compounds the almond shell, oil (cold press) as well as the paste (kernel + skin) resulting from the oil extraction process. Significant differences $(p>0.05)$ were found both in the yield 


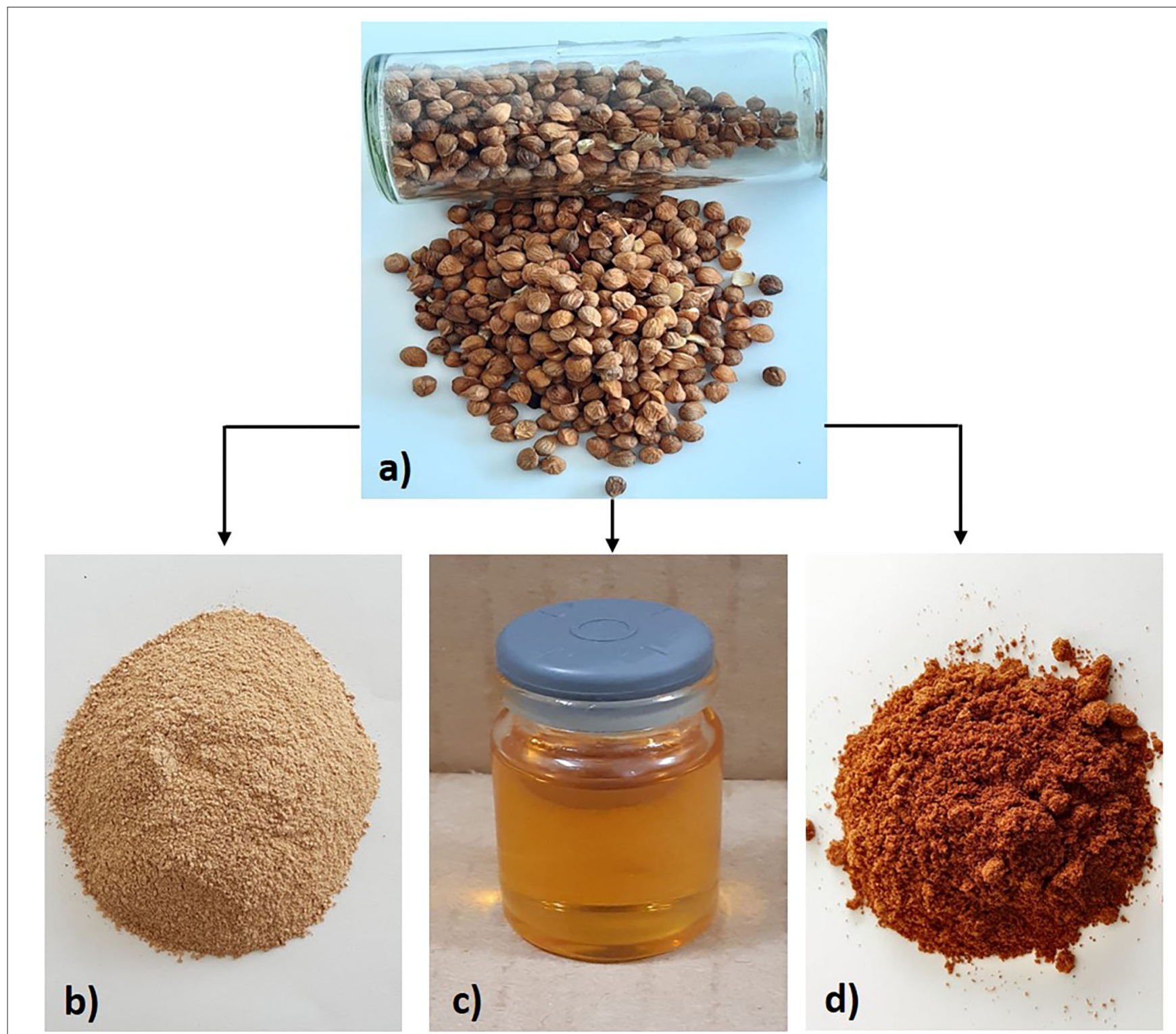

FIGURE 2 | (a) P. serotina (var. capuli) seed and their by-products; (b) shell, (c) oil and, (d) paste.

of the solvents and in the extraction of the phenolic compounds. In the case of the shell, ethanol presented the highest yield as a solvent (70.53\%; $1.01 \pm 0.05 \mathrm{mg} \mathrm{GAE} / \mathrm{g})$. However, methanol was the most effective for the extraction of total phenolic compounds (43.07\%; $1.65 \pm 0.06 \mathrm{mg}$ GAE/g). In addition, the acidified water presented a solvent yield of $62.87 \%$, with a total phenol content of $0.97 \pm 0.12 \mathrm{mg} \mathrm{GAE} / \mathrm{g}$. On the other hand, the lowest yield was for acetone with values of $24.33 \%$ and $1.19 \pm$ $0.04 \mathrm{mg} \mathrm{GAE} / \mathrm{g}$. Regarding paste, the highest solvent yield was for methanol (70.20\%; $0.79 \pm 0.03 \mathrm{mg} \mathrm{GAE} / \mathrm{g})$, yet the total phenolic content was higher in the extraction with acidified water $(58.00 \%$; $1.42 \pm 0.14 \mathrm{mg} \mathrm{GAE} / \mathrm{g}$ ). In addition, the total phenolic content was similar with the extractions with ethanol (45.20\%; $0.72 \pm$ $0.02 \mathrm{mg} \mathrm{GAE} / \mathrm{g}$ ) and acetone (20.67\%; $0.72 \pm 0.05 \mathrm{mg} \mathrm{GAE} / \mathrm{g}$ ), respectively (Figure 3). Moreover, in the case of oil, although the solvent yields were higher for acidified water $(90.33 \%$; $0.02 \pm 0.01 \mathrm{mg} \mathrm{GAE} / \mathrm{g}$ ) and ethanol (90.20\%; $0.25 \pm 0.02 \mathrm{mg}$ $\mathrm{GAE} / \mathrm{g}$ ), the total phenolic content was higher in the acetone extraction $(20.87 \% ; 0.47 \pm 0.00 \mathrm{mg}$ GAE/g). Finally, the yield in the extraction with methanol was $87.13 \%$ and the total phenolic content was $0.05 \pm 0.01 \mathrm{mg}$ GAE/g (Figure 3). In general, it can be observed that the use of different solvents significantly influenced the obtaining of total phenolic compounds from the various by-products.

\section{Flavonoid Content Determination}

As shown in Figure 4, a significant difference $(p>0.05)$ was found regarding the content of total flavonoids in the various byproducts of the almond. The highest values were found in the paste, and the lowest values in the oil $(0.78 \pm 0.02 \mathrm{mg}$ and 0.34 


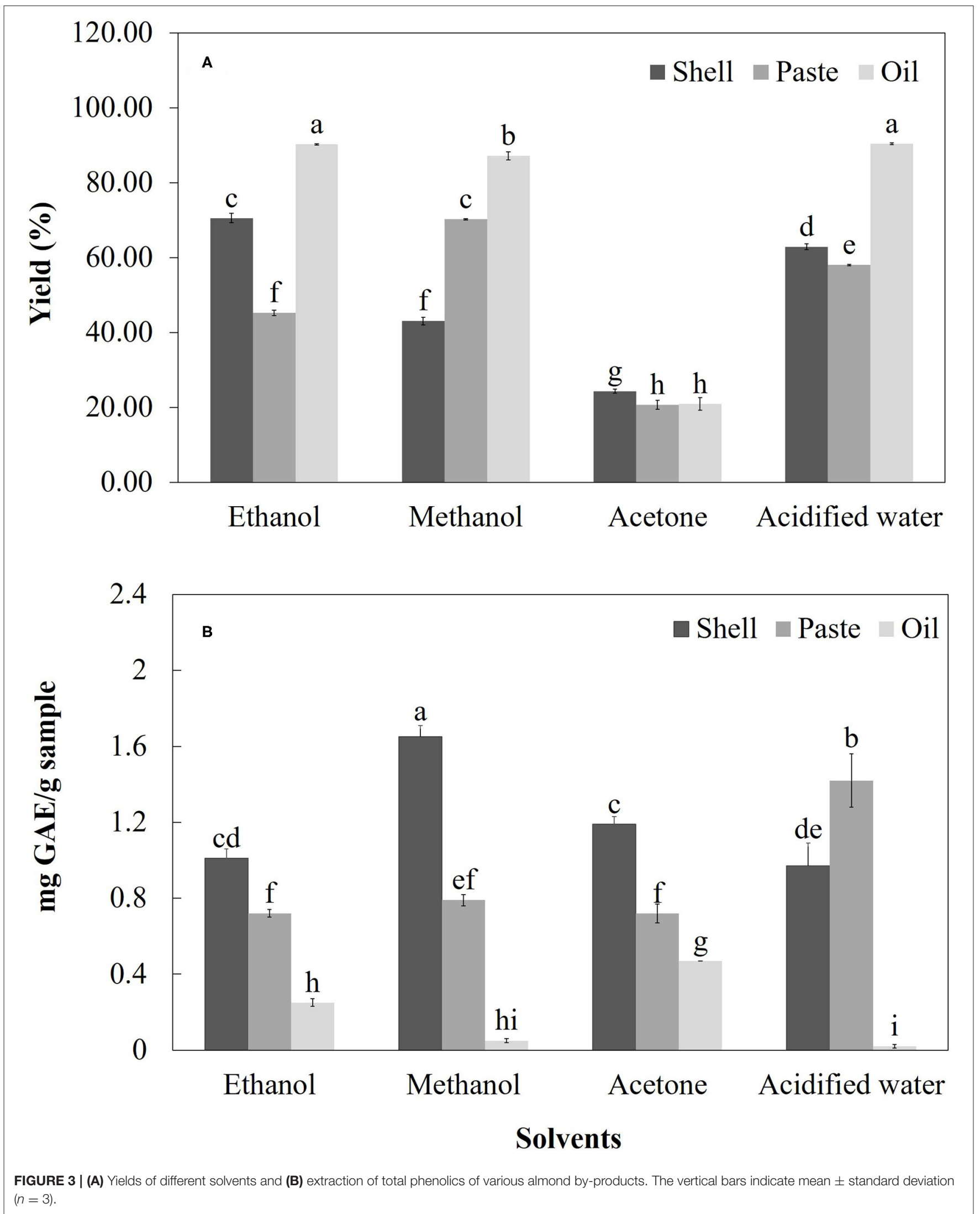




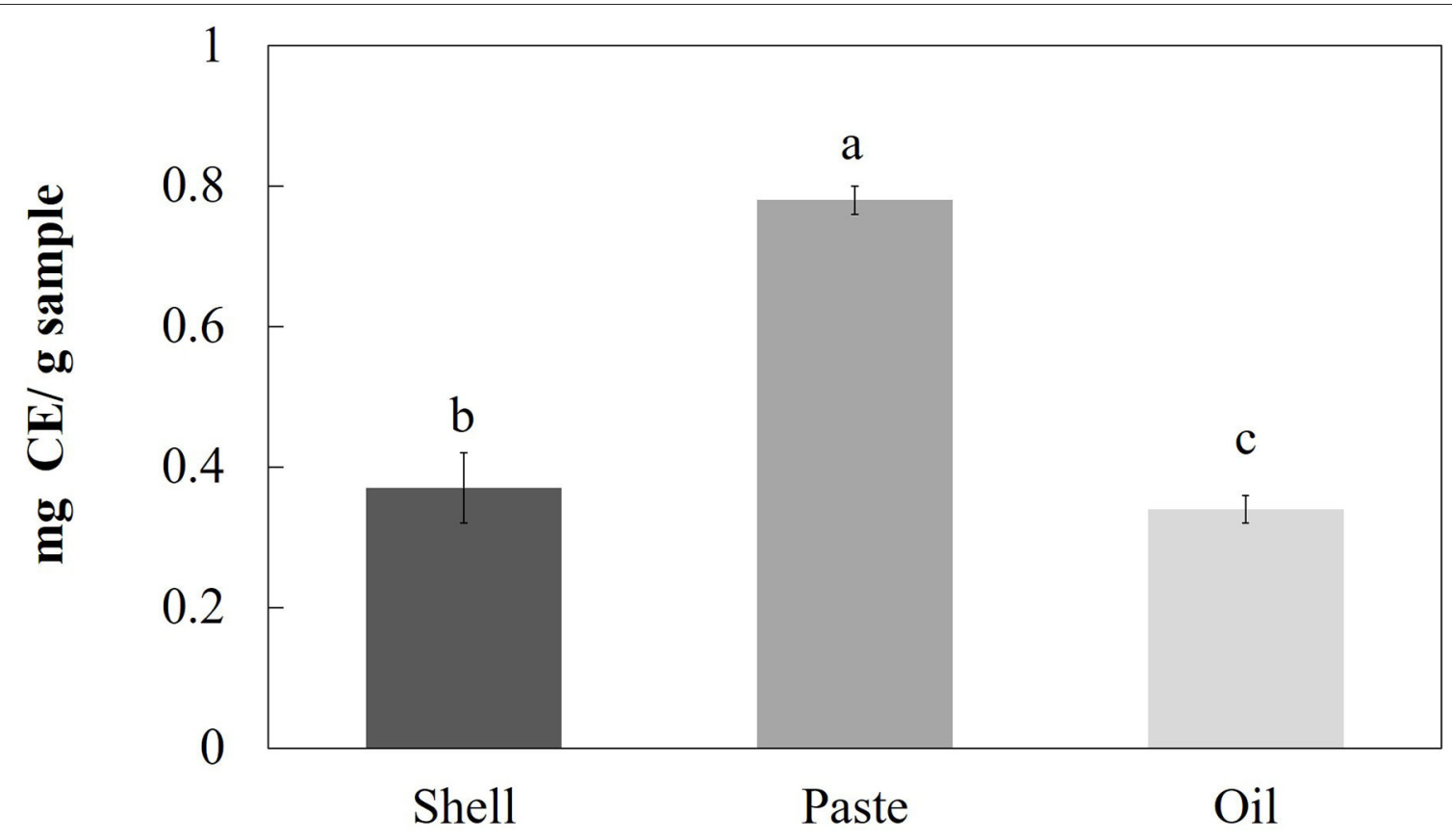

\section{Treatments}

FIGURE 4 | Flavonoid content of various almond by-products extracted with ethanol. The vertical bars indicate mean \pm standard deviation $(n=3)$.

$\pm 0.02 \mathrm{mg} \mathrm{EC} / \mathrm{g}$, respectively). In the case of shell, the content of total flavonoids was $0.37 \pm 0.05 \mathrm{mg} \mathrm{EC/g}$.

\section{Antioxidant Activity Determination}

Regarding the antioxidant activity measured by the DPPH and ABTS methods, a significant difference $(p>0.05)$ was found between the different treatments. In both methods, the highest values were for oil, followed by shell and paste. The antioxidant activity values found in the shell were $1,527.78 \pm 268.6978 \mu \mathrm{M}$ $\mathrm{TE} / \mathrm{g}(\%$ inhibition $=10.77 \pm 1.89)$ and $568.45 \pm 22.47 \mu \mathrm{M} \mathrm{TE} / \mathrm{g}$ (\% inhibition $=7.04 \pm 0.28$ ) for ABTS and DPPH, respectively (Figures 5, 6). On the other hand, the antioxidant activity values of the pasta were $1,229.17 \pm 587.78 \mu \mathrm{M} \mathrm{TE} / \mathrm{g}$ with a $\%$ inhibition of $8.66 \pm 4.14$ (ABTS) and $562.50 \pm 49.71 \mu \mathrm{M}$ TE/g with a $\%$ inhibition of $6.97 \pm 0.62(\mathrm{DPPH})$ (Figures 5, 6). Finally, in the case of oil, the antioxidant activity values obtained in this research were $18,894.44 \pm 1,625.18 \mu \mathrm{M}$ TE/g with a $\%$ inhibition of 32.50 \pm 2.86 and $4,369.05 \pm 114.81 \mu \mathrm{M} \mathrm{TE} / \mathrm{g}$ with a $\%$ inhibition of $13.532 \pm 0.36$ (Figures 5, 6).

\section{DISCUSSION}

\section{Solvent Yields and Extraction of Total Phenolics}

In the case of the shell, the results found in terms of solvent yield indicated that, although ethanol presented the highest yields, methanol was the most effective solvent for the extraction of total phenolic compounds (Figure 3); this effect is in line with that reported by Pinelo et al. (26) during the extraction of antioxidant phenolics from almond hulls. Moreover, although the acidified water presented a good yield as a solvent, it also showed the lowest value in the total phenol content; this finding is similar to that reported by Jiménez et al. (34). Moreover, although the acetone showed a total phenol content similar to that obtained by ethanol, it also showed the lowest yield (Figure 3); this effect could be related to the high volatility of the acetone with respect to other solvents. Finally, the values of the total phenol content of the almond shell found in this research are lower than those reported in $P$. dulcis $(21,22,35,36), P$. amygdalus $(33,37)$, and $P$. serotina Ehrh (7). However, they are similar to those reported by Moure et al. (24) in P. amygdalus and Bolling et al. (38) in California almonds. In the case of paste, although the yield was higher for methanol, the total phenolic content was higher in the extraction with acidified water (Figure 3). Compared with previous studies, the content of total phenols found in this study was lower than that reported in various commercial $P$. dulcis cultivars $(39,40)$ and higher than that reported in various genotypes of $P$. amygdalus almond (16). In the case of oil, although the highest yields were found in ethanol and acidified water, the highest total phenol content was found in acetone as a solvent (Figure 3). Compared with other studies, the content of total phenols of the oil obtained in this research was lower than that reported by Mezzomo et al. (41) in peach $(P$. persica) almond oil and higher than that reported by Miraliakbari (42) in P. dulcis oil.

In general, the highest content of total phenols was found in the shell, followed by the paste and the oil. These findings are in agreement with those reported by Isfahlan et al. (37) in Iranian 

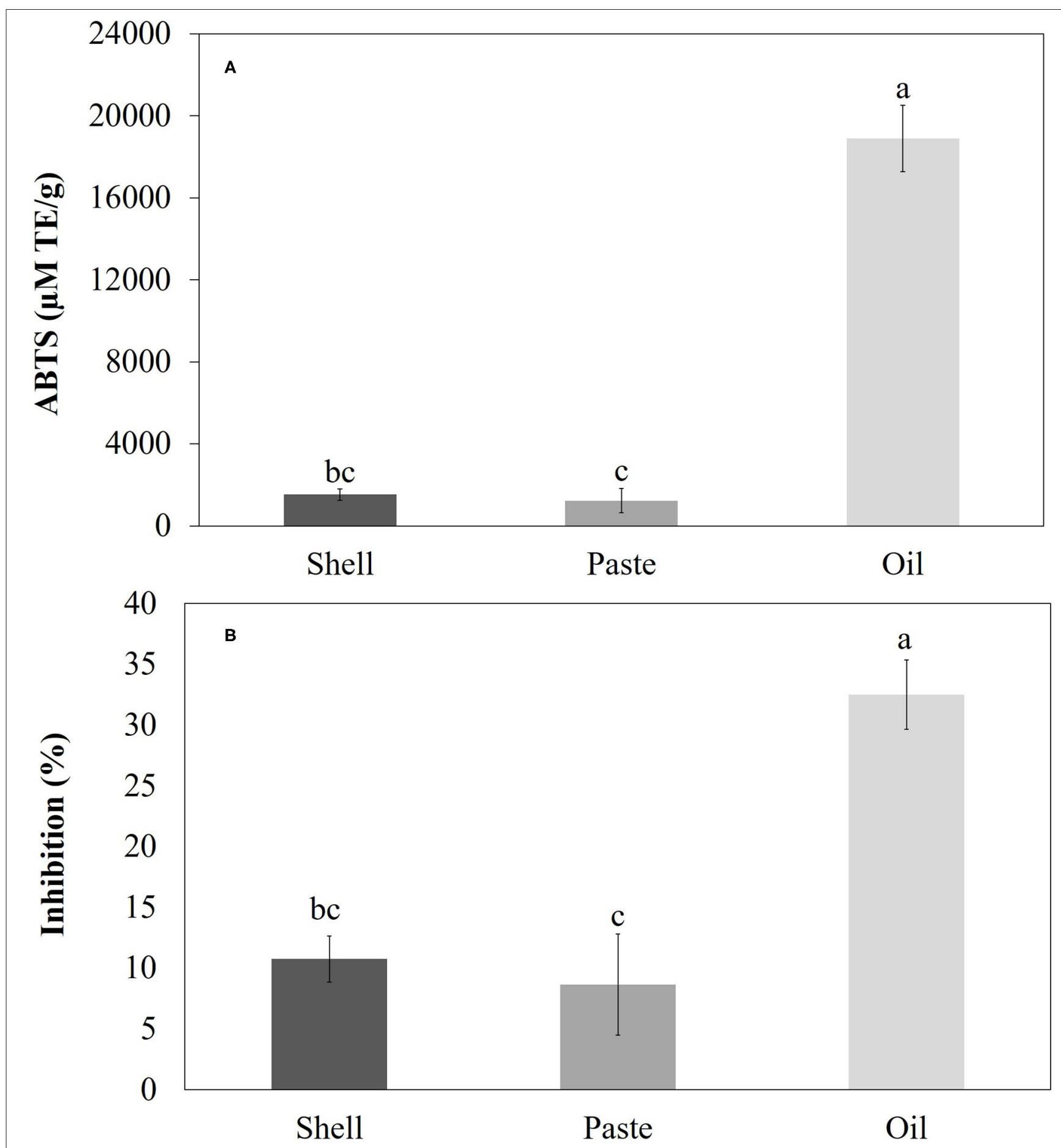

Almond by-products

FIGURE 5 | (A) Antioxidant activity and (B) ABTS radical scavenging activity of various almond by-products extracted with ethanol. The vertical bars indicate mean \pm standard deviation $(n=3)$.

almond, indicating that the outer layers of the almond, such as the shell, contain a greater amount of phenolic compounds linked to the components of the cell wall, such as proteins and polysaccharides, and their purpose is to protect internal materials. Likewise, Luna-Vázquez et al. (7) report a higher content of total phenolic compounds in the peel of Black Cherry 


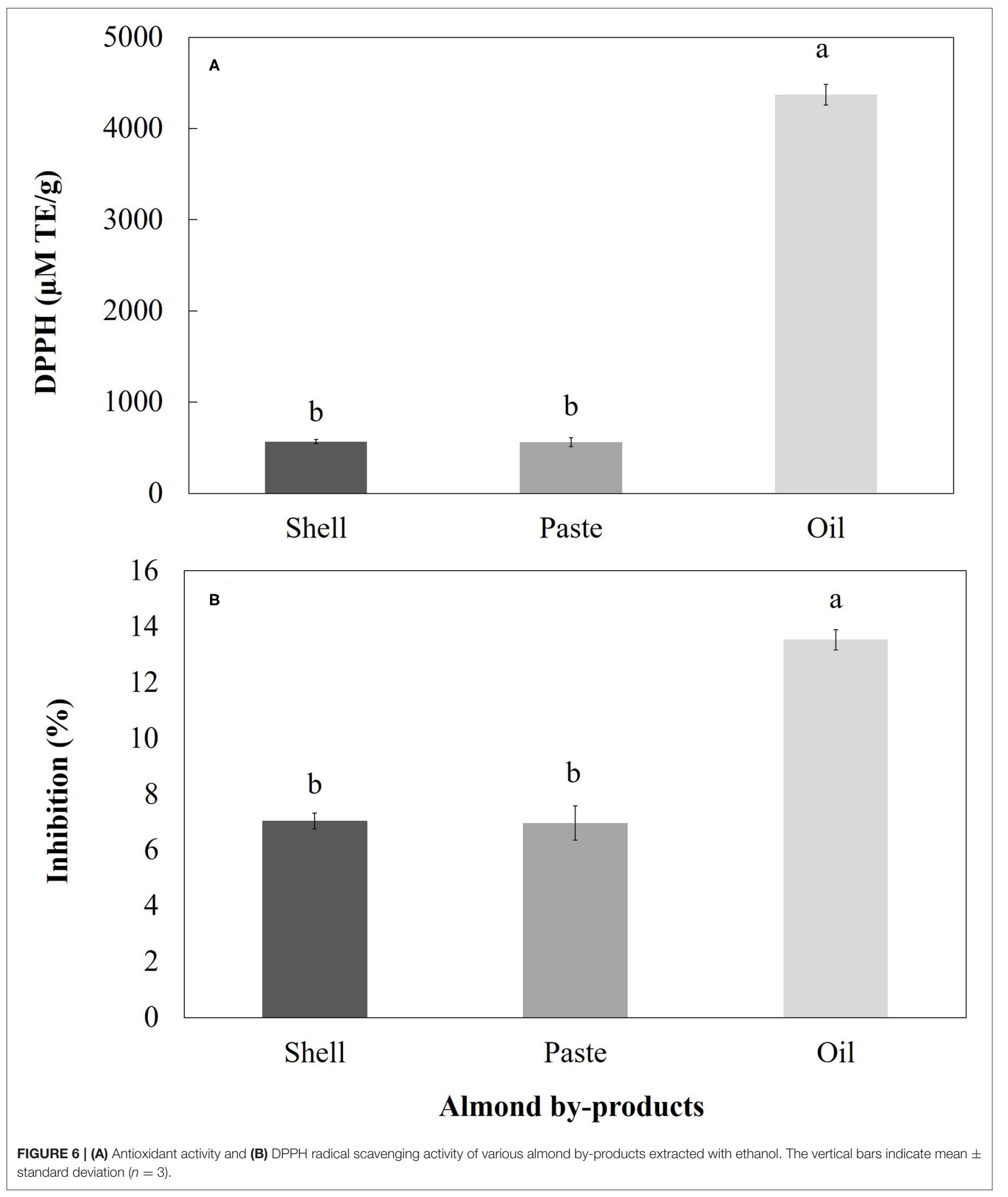

$P$. serotina compared to the flesh. In addition, the differences in our results with respect to that reported in other research could be associated with the diversity of the almond species (43), the cultivars, the growing regions, and environmental factors, as well as the product's harvest season, among others $(11,39)$. Furthermore, it is important to mention that the total phenol 
content is also influenced by the solvent used in the extraction process $(2,26,37)$. Finally, in order to homologate the use of the solvent in the extraction process of the bioactive compounds from almond by-products, we decided to use ethanol as solvent in the subsequent evaluations since it showed a good yield and total phenol $(26,34)$.

\section{Flavonoid Content Analysis}

Flavonoids are a group of phenolic compounds that includes anthocyanidins, isoflavones, flavanones, flavonols, and flavanols, among others (19). These compounds are associated with beneficial effects due to their wide variety of antioxidant properties (they act as scavengers of free radicals), antimicrobial, anti-inflammatory, anticancer, vasodilatory, among others (33, 39). As mentioned in the Results section, the total flavonoid content was higher in the almond paste, followed by the shell and oil (Figure 4). In the case of pasta, the content of total flavonoids found in this research (Figure 4) was higher than that reported in $P$. serotina Ehrh (7), but lower than that reported in P. dulcis $(39,40), A$. pabotti and A. korschinskii (43). On the other hand, in the case of the shell, our results (Figure 4) showed a lower content of flavonoids than that reported in P. dulcis (21), but a higher content compared to that reported in P. serotina Ehrh (7); This effect may be associated with the variety of the almond and with the seasonal harvest of the product (38). Finally, the total flavonoid values found in the oil (Figure 4) were higher than those reported by Karaman et al. (44) in different cold press edible oil by-products (almond, walnut, pomegranate, and grape), but very similar to that reported in a previous study conducted by our research group (25). In general, most of the flavonoids in almonds are present in the external part of the fruit, acting almost exclusively on the skin and protecting the seed against environmental stress (37).

\section{Antioxidant Activity Evaluations}

The antioxidant activity of almonds is attributed to its content of phenolic compounds in various parts of the fruit, such as the hull, shell, skin and, kernel, whose main components are phenolic acids (e.g., non-flavonoids such as benzoic acids and cinnamic acids), and flavonoids (e.g., flavanols, flavonols, flavanones and procyanidins) (12). As shown in the Results section, regarding the antioxidant activity measured by the DPPH and ABTS methods, the highest values were found in the oil, followed by the shell and paste (Figures 5, 6, respectively). The antioxidant activity values found in the shell are lower than those reported in P. serotina Ehrh by Luna-Vázquez et al. (7) but similar to those reported in some genotypes (S1-1, S4-3 and S4- 6) of P. amygdalus (33), and $P$. dulcis (21). On the other hand, the antioxidant activity values found in pasta (Figures 5, 6) are lower than those reported in $P$. serotina Ehrh. (7) and P. amygdalus L. $(16,43)$, but higher than those reported by Summo et al. (11) in P. dulcis. Finally, in the case of oil, the antioxidant activity values obtained in this research (Figures 5, 6) were similar to those reported in $P$. serotina by LuMartínez et al. (25) and higher than those reported in $P$. dulcis by Miraliakbari (42). Finally, as mentioned in the previous sections, the fluctuations in terms of the results found in this research and the studies reported in the literature can be attributed to the diversity of species and varieties within almond species (7).

In general, although the content of phenolic compounds was higher in the shell, the pasta showed the highest content of flavonoids. In addition, the highest antioxidant activity was found in the oil; this effect may be associated with the content of phenolic compounds and to the presence of non-phenolic compounds with antioxidant activity such as terpenoids (sterols and triterpenoids) (12).

\section{CONCLUSIONS}

It was possible to obtain phenolic compounds from almond byproducts, such as shell, paste, and oil using various solvents. In general, it can be observed that the use of different solvents significantly influenced the obtaining of total phenolic compounds from the various by-products. In the shell, ethanol showed the highest yields, but methanol was the most effective solvent for obtaining the total phenolic compounds. Regarding paste, although the yield was higher for methanol, the total phenolic content was higher in the extraction with acidified water. In addition, ethanol and acidified water showed the highest yields in the case of oil, but acetone was the most effective solvent for obtaining total phenolic compounds. In general, the highest content of total phenols was found in the shell, followed by the paste and the oil. Particularly, regarding total flavonoid content extracted with ethanol, the highest values were found in the paste, followed by the shell and oil. Moreover, regarding antioxidant activity obtained by ABTS and DPPH methods, the highest values were found in the oil, followed by the shell and paste. Finally, our results suggest that by-products such as the shell, paste, and oil obtained from Prunus serotina var capuli represent a potential alternative for the recovery of bioactive compounds with antioxidant activity, such as phenolic compounds and flavonoids. However, as prospects, it is recommended to continue with this research to determine various factors affecting the extraction of bioactive compounds and characterize the phytochemical compounds (e.g., polyphenols and flavonoids) found in the shell, oil and, paste of the Capuli almond, since these compounds are of interest due to their wide variety of properties associated with beneficial health effects.

\section{DATA AVAILABILITY STATEMENT}

The raw data supporting the conclusions of this article will be made available by the authors, without undue reservation.

\section{AUTHOR CONTRIBUTIONS}

JB-G, EG-M, MT-G, and CG-R: conceptualization. AL, MT-G, EGM, JB-G, CA-G, CA, and CG-R: investigation. CG-R, MT-G, and AL: writing-original draft preparation. MT-G, CG-R, EG-M, and JB-G: writing-review and editing. All authors contributed to the article and approved the submitted version. 


\section{FUNDING}

This research was funded by Program of Support for Research, Science and Technology, PAICYT, UANL, CT723-19.

\section{REFERENCES}

1. Guzman FA, Segura SD, Almaguer G. Blackberry (Prunus serotina Ehrh): a multipurpose tree with forestry potential in México. Madera y Bosques. (2020) 26:1-15. doi: 10.21829/myb.2020.2611866

2. McVaugh. Prunus serotina. Brittonia. (1949) 7:227-9.

3. Government of México. Estatistical yearbook of agricultural production. (2020). Available online at: https://nube.siap.gob.mx/cierreagricola/ (accessed January 21, 2021).

4. Ullah H, De Filippis A, Khan H, Xiao J, Daglia M. An overview of the health benefits of Prunus species with special reference to metabolic syndrome risk factors. Food Chem Toxicol. (2020) 144:1-12. doi: 10.1016/j.fct.2020.111574

5. Javaid T, Mahmood S, Saeed W, Qamrosh M. A critical review in varieties and benefits of almond (Prunus dulcis). ASNH. (2019) 3:702. doi: 10.31080/ASNH.2019.03.0489

6. Palomares F, Rojas IS, Palencia G, Jimenez MA, Macias ML, González A, et al. In vitro and in vivo cysticidal activity of extracts and isolated flavanone from the bark of Prunus serotina: a bio-guided study. Acta Trop. (2017) 170:1-7. doi: 10.1016/j.actatropica.2017.02.023

7. Luna-Vázquez FJ, Ibarra-Alvarado C, Rojas-Molina A, Rojas-Molina JI, Yahia EM, Rivera-Pastrana DM, et al. Nutraceutical value of black cherry Prunus serotina Ehrh. fruits: antioxidant and antihypertensive properties. Molecules. (2013) 18:14597-612. doi: 10.3390/molecules181214597

8. García L, Rojas A, Ibarra C, Rojas JI, Vázquez PA, Luna FJ, et al. Nutritional value and volatile compounds of black cherry (Prunus serotina) seeds. Molecules. (2015) 20:3479-95. doi: 10.3390/molecules20023479

9. Esfahlan AJ, Jahanban A, Jamei R, Esfahlan RJ. Review the importance of almond (Prunus amygdalus L.) and its by-products. Food Chem. (2010) 120:349-60. doi: 10.1016/j.foodchem.2009.09.063

10. Lu-Martínez A, Báez JG, Bautista M, Galindo SA, García E. Studied of defatted flour and protein concentrated of Prunus serotine and applications. Foods. (2020) 9:2-22. doi: 10.3390/foods9010029

11. Summo C, Palasciano M, De Angelis D, Paradiso VM, Caponio F, Pasqualone A. Evaluation of the chemical and nutritional characteristics of almonds (Prunus dulcis (Mill). D.A.Webb) as influenced by harvest time and cultivar. $J$ Sci Food Agric. (2018) 98:5647-55. doi: 10.1002/jsfa.9110

12. Prgomet I, Gonçalves B, Domínguez-Perles R, Pascual-Seva N, Barros, AIRNA. Valorization challenges to almond residues: phytochemical composition and functional application. Molecules. (2017) 22:1774. doi: 10.3390/molecules22101774

13. Milbury PE, Chen CY, Dolnikowski GG, Blumberg JB. Determination of flavonoids and phenolics and their distribution in almonds. J Agric Food Chem. (2006) 54:5027-33. doi: 10.1021/jf0603937

14. Amico V, Barresi V, Condorelli D, Spatafora C, Tringali C. Antiproliferative terpenoids from almond (Prunus dulcis): Identification and structure- activity relationships. J Agric Food Chem. (2006) 54:810-4. doi: 10.1021/jf052812q

15. Telichowska A, Kobus J, Szulc P. Review phytopharmacological possibilities of bird cherry Prunus padus L and Prunus serotina L species and their bioactive phytochemicals. Nutrients. (2020) 12:1-21. doi: 10.3390/nu12 071966

16. Özcan MM, Matthäus B, Aljuhaimi F, Mohamed IAA, Ghafoor K, Babiker EE, et al. Effect of almond genotypes on fatty acid composition, tocopherols and mineral contents and bioactive properties of sweet almond (Prunus amygdalus Batsch spp dulce) kernel and oils. J Food Sci Technol. (2020) 57:4182-92. doi: 10.1007/s13197-020-04456-9

17. Musarra M, Ginestra G, Smeriglio A, Pennisi R, Sciortino MT, Mandalari G. The antimicrobial and antiviral of polyphenols from Almond (Prunus dulcis L.) skin. Nutrients. (2019) 11:1-11. doi: 10.3390/nu11102355

\section{ACKNOWLEDGMENTS}

We thank the thematic Network 12.3 to reduce and value food losses and waste toward sustainable food systems financed by CONACYT for their support in carrying out this project.

18. Liu Z, Lin X, Huang G, Zhang W, Rao P, Ni L. Prebiotic effects of almonds and almond skins on intestinal microbiota in healthy adult humans. Anaerobe. (2014) 26:1-6. doi: 10.1016/j.anaerobe.2013.11.007

19. Barreca D, Nabavi SM, Sureda A, Rasekhian M, Raciti R, Sanches-Silva A, et al. Almonds (Prunus Dulcis Mill. D. A. Webb): a source of nutrients and healthpromoting compounds. Nutrients. (2020) 12:672. doi: 10.3390/nu12030672

20. Aguerrebere IA, Rojas A, Dave B, Drover JG. Characteristics of Prunus serotina seed oil. Food Chem. (2011) 124:98390. doi: 10.1016/j.foodchem.2010.07.040

21. Queirós CSGP, Cardoso S, Lourenço A, Ferreira J, Miranda I, Lourenço MJV, et al. Characterization of walnut, almond, and pine nut shells regarding chemical composition and extract composition. Biomass Convers Biorefin. (2020) 10:175-88. doi: 10.1007/s13399-019-00424-2

22. Smeriglio A, Mandalari G, Bisignano C, Filocamo A, Barreca D, Bellocco E, et al. 2016. Polyphenolic content and biological properties of Avola almond (Prunus dulcis Mill. D.A. Webb) skin and its industrial byproducts. Ind Crop Prod. (2016) 83:283-93. doi: 10.1016/j.indcrop.2015.11.089

23. Sfahlan AJ, Mahmoozahed A, Hasaanzadeh A, Heidari R, Jamei R. Antioxidants and antiradicals in almond hull and shell (Amygdalus communis L.) as a function of genotype. Food Chem. (2009) 115:52933. doi: 10.1016/j.foodchem.2008.12.049

24. Moure A, Pazos M, Medina I, Domínguez H, Parajó JC. Antioxidant activity of extracts produced by solvent extraction of almond shells acid hydrolysates. Food Chem. (2007) 101:193-201. doi: 10.1016/j.foodchem.2006.01.017

25. Lu-Martínez AA, Báez-González JG, Castillo-Hernández S, Amaya-Guerra C, Rodríguez-Rodríguez J, García-Márquez E. Studied of Prunus serotine oil extracted by cold pressing and antioxidant effect of $P$. longiflora essential oil. J Food Sci Technol. (2020) 58:1420-9. doi: 10.1007/s13197-020-04653-6

26. Pinelo M, Rubilar M, Sinero J, Núñez MJ. Extraction of antioxidant phenolics from almond hulls (Prunus amygdalus) and pine sawdust (Pinus pinaster). Food Chem. (2004) 85:267-73. doi: 10.1016/j.foodchem.2003.06.020

27. Bail S, Stuebiger G, Krist S, Unterweger H, Buchbauer G. Characterization of various grape seed oils by volatile compounds, triacylglycerol, composition, total phenols and antioxidant capacity. Food Chem. (2008) 108:112232. doi: 10.1016/j.foodchem.2007.11.063

28. Samudra S, Siriwardhana W. Almond as a source of natural antioxidants. Canada. Memorial University of Newfoundland. (2001). Available online at: https://research.library.mun.ca/8628/1/Siriwardhana_Wijeratne.pdf (accessed January 18, 2021).

29. Singleton VL, Orthofer R, Lamuela RM. Analysis of total phenols and other oxidation substrates and antioxidants by means of Folin-Ciocalteu reagent. Meth Enzymol. (1999) 299:152-78. doi: 10.1016/S0076-6879(99)99017-1

30. Miraliakbari H, Shahidi F. Antioxidant activity of minor components of tree nut oils. Food Chem. (2008) 111:421-7. doi: 10.1016/j.foodchem.2008.04.008

31. Fernandes L, Casal S, Cruz R, Pereira JA, Ramalhosa E. Seed oils ten traditional Portuguese grape varieties with interesting chemical and antioxidant properties. Food Res Int. (2013) 50:161-6. doi: 10.1016/j.foodres.2012.09.039

32. Pinheiro AC, Monalise A, Fett JM. Antioxidant properties of pecan nut [Carya illinoinensis (Wangenh.) C. Koch] shell infusion. Grasas y aceites. (2009) 60:330-5. doi: 10.3989/gya.107708

33. Moosavi DKS, Dehghan G, Hosseini S, Jahanban Esfahlan A. Effect of fiveyear storage on total phenolic content and antioxidant capacity of almond (Amygdalus communis L.) hull and shell from different genotypes. Avicenna J Phytomed. (2015) 5:26-33.

34. Jiménez M, Castillo I, Azuara E, Beristain CI. Actividad antioxidante y antimicrobiana de extractos de Capulin (Prunus serotina subsp capuli). Rev Mex Ing Quim. (2011) 10:29-37. 
35. Garrido I, Monagas M, Gómez-Cordovés C, Bartolomé B. Polyphenols and antioxidant properties of almond skins: influence of industrial processing. $J$ Food Sci. (2008) 73:C106-15. doi: 10.1111/j.1750-3841.2007.00637.x

36. Prgomet I, Gonçalves B, Domínguez-Perles R, Santos R, Saavedra MJ, Aires A, et al. Irrigation deficit turns almond by-products into a valuable source of antimicrobial (poly)phenols. Ind Crop Prod. (2019) 132:18696. doi: 10.1016/j.indcrop.2019.02.024

37. Isfahlan AJ, Mahmoodzadeh A, Hassanzade A, Heidari R, Jamei R. Antioxidant and antiradical activities of phenolic extracts from Iranian almond (Prunus amygdalus L.) hulls and shells. Turk J Biol. (2010) 34:165-73. doi: 10.3906/biy-0807-21

38. Bolling BW, Dolnikowski G, Blumberg JB, Chen CYO. Polyphenol content and antioxidant activity of California almonds depend on cultivar and harvest year. Food Chem. (2010) 122: 819-25. doi: 10.1016/j.foodchem.2010. 03.068

39. Barreira JCM, Ferreira ICFR, Oliveira MBPP, Pereira JA. Antioxidant activity and bioactive compounds of ten Portuguese regional and commercial almond cultivars. Food Chem Toxicol. (2008) 46:2230-5. doi: 10.1016/j.fct.2008. 02.024

40. Keser S, Demir E, Yilmaz O. Phytochemicals and antioxidant activity of the almond kernel (Prunus dulcis Mill.) from Turkey. J Chem Soc Pak. (2014) 36:534-41.

41. Mezzomo N, Mileo BR, Friedrich MT, Martínez J, Ferreira SRS. Supercritical fluid extraction of peach (Prunus persica) almond oil: process yield and extract composition. Bioresour Technol. (2010) 101:5622-32. doi: 10.1016/j.biortech.2010.02.020

42. Miraliakbari H. Tree nut oils: chemical characteristics, oxidation and antioxidants (thesis of Master of Science). Memorial University of Newfoundland, Canada (2005).

43. Esfahlan A, Jamei R. Properties of biological activity of ten wild almond (Prunus amygdalus L.) species. Turk J Biol. (2012) 36:201-9. doi: 10.3906/biy-1101-174

44. Karaman S, Karasu S, Tornuk F, Toker OS, Geçgel Ü, Sagdic O, et al. Recovery potential of cold press byproducts obtained from the edible oil industry: physicochemical, bioactive, and antimicrobial properties. J Agric Food Chem. (2015) 63: 2305-2313. doi: 10.1021/jf504390t

Conflict of Interest: The authors declare that the research was conducted in the absence of any commercial or financial relationships that could be construed as a potential conflict of interest.

Copyright (C) 2021 Gallardo-Rivera, Lu, Treviño-Garza, García-Márquez, AmayaGuerra, Aguilera and Báez-González. This is an open-access article distributed under the terms of the Creative Commons Attribution License (CC BY). The use, distribution or reproduction in other forums is permitted, provided the original author(s) and the copyright owner(s) are credited and that the original publication in this journal is cited, in accordance with accepted academic practice. No use, distribution or reproduction is permitted which does not comply with these terms. 